\title{
Research on Agricultural Internet of Things Information Collection and Control System
}

\section{Hongwei Zhu}

Jilin Agricultural Science and Technology University, Jilin, Jilin, 132000

\author{
Keywords: Agricultural Products, Internet of Things, Information Collection
}

\begin{abstract}
In order to enhance the informatization and intelligence level of the integrated agricultural park and improve farm production efficiency and efficiency, a software and hardware structure of the agricultural information networking and back-end intelligent control system for agriculture park was designed. Information acquisition equipment of IoT Agricultural intelligent control equipment; front-end information collection with sensor nodes, wireless transmission network and sensor configuration for information collection, back-end intelligent control system combined with expert systems, agricultural intelligent frequency conversion irrigation system, automatic greenhouse control system for intelligent control. The system and instrument developed in Haining, Zhejiang Province have received good results and achieved good economic and ecological benefits, which is of great significance to the modernized agricultural informatization and intelligent development.
\end{abstract}

\section{Introduction}

With the continuous growth of our population and the declining area of arable land, it is imperative to develop facilities agriculture and realize the sustainable development of agriculture. Facilities Agriculture is an industry with certain facilities that can effectively improve environmental and meteorological factors in local areas and provide good environmental conditions for plant growth and development. The purpose of facility agriculture is to achieve resource conservation and environmental protection based on improving agricultural production efficiency and yield. Vigorously developing facilities agriculture is an effective way to take China's agriculture modernization. It is of great significance for optimizing industrial structure, promoting agricultural modernization, improving economic efficiency, increasing farmers' income, and improving agricultural ecological environment.

Internet of Things technology is currently attracting much attention in the world. It involves the frontier hot research areas that are highly interdisciplinary and have a high degree of knowledge integration.

It integrates sensor technology, embedded computing technology, modern network and wireless communications technology, distributed information processing technology, etc., through various integrated micro-sensor collaborative real-time monitoring, sensing and acquisition of various environmental or monitoring object information These messages are sent wirelessly and delivered to user terminals in an ad hoc, multi-hop network so that connectivity between the physical world, the computing world, and the ternary world of human society can be realized. The combination of information technology and intelligent technologies and facilities and agriculture in the Internet of Things will surely be the necessary way and an important realization method for the agricultural modernization in the future. In this paper, an agricultural IOT system is designed for the modern integrated agricultural park in Haining Minsheng Fruit and Vegetable Professional Cooperative, and corresponding instruments and equipment for real-time rapid acquisition, wireless transmission and intelligent control of agricultural ecological information are developed. For each area in the facility agricultural park, Of the soil, plant and environment information collected in real time, accurate and rapid, so that users can according to the collected information through the computer for digital analysis and processing to diagnose the growth of plants and yield the reasons for the spatial differences, and for different Scientific decision-making is made to the target, and then precise 
irrigation, fertilization and spraying are carried out to maximize the utilization efficiency of water, fertilizers and pesticides, reduce the impact of plant diseases and insect pests, reduce the damage to the soil and the negative impact on the ecological environment, Increase agricultural output while reducing production costs and protecting the environment.

\section{Construction of Agricultural Information Service System under Internet of Things}

We should attach great importance to the collection of information resources so as to meet the diversified information needs of users as the starting point and the foothold of agricultural information services to the full extent so as to fully investigate and understand the individual needs and provide the government and the broad masses of farmers with comprehensive, multiPersonalized, informative information services.

Give full play to the guidance of government policies, financial support and the role of Jiangsu Provincial Commission of Agricultural Development as an integrated agricultural functional department, coordinate and make efforts to integrate the superior information resources of various information service providers, and make unified planning based on the principle of marketization Management, multi-party coordination, to avoid the repeated development of information resources, to maximize the effective sharing and utilization of information resources.

First, make full use of the technical advantages of Internet of Things. Agricultural Internet of Things (IoT) is one of the important applications of IoT technology. With the advancement of science and technology, the traditional agricultural information service model ushers in new opportunities and challenges for change. "The publication of the" Twelfth Five-Year Development Plan for Jiangsu's Internet of Things Industry "provides a good policy support environment for the application of Internet of Things in Jiangsu Province. Facing opportunities for development and challenges, the technological advantage of making full use of the Internet of Things It runs through the main line of service owners, objects and service contents in the agricultural information service system. It is also an important technical support for the construction of agricultural information service system in Jiangsu Province.

Second, in-depth development of agricultural information service resources. All along, the main mode of agricultural information service in Jiangsu Province is all levels of government, agricultural committees and local agricultural departments, policy support for agricultural information services with rapid changes, but at the same time, the unity of the main service has also led to agriculture Inadequate development of service resources. To construct agricultural information service system in IoT environment, we must maximize the use of agricultural information service resources and actively integrate various service resources so that service objects can truly enjoy the benefits of the transformation and upgrading of supporting services brought by technological innovation.

Third, vigorously integrate the agricultural information service team. With the strong support of Jiangsu Province for the development of agricultural Internet of Things, a batch of batch service units, enterprises, intermediary agencies and various research organizations in relevant fields came into being, which also means the expansion of the main ranks of potential agricultural information service providers. A well-functioning service system must be inseparable from the growth of the main information service team. Therefore, the construction of agricultural information service system should make great efforts to integrate the main body of agricultural information service in the province, give full play to the diversification advantages of service subjects and make effective use of innovative advantages of emerging service organizations and individuals.

Fourth, try our best to improve the agricultural information service guarantee system. Improving the quality of agricultural information service has always been a hot issue that attaches great importance to by agricultural informatization builders. An efficient agricultural information service system can not be separated from its perfect service guarantee system. It is an important support for the information service system to play a long-term role and is also a strong backing for pioneering and innovation in agricultural informatization construction. 


\section{System of Information Services}

The basic of agricultural information service is to promote the rapid development of agricultural industry. Therefore, agricultural production information is one of the key contents of agricultural information service. Agricultural production information mainly includes crop growth information, seed and breeding skills, application information of emerging technologies and various agricultural production solutions. Among them, the crop growth information is partly obtained by agricultural operators based on their own production experience, and the other part is through the feedback of information service providers. The application of IOT technology can find out the problems in the process of crop growth in a more timely manner and provide corresponding decision-making suggestions through various channels of information service platform. Breeding and breeding skills can usually be transmitted to agricultural operators through traditional modes of information dissemination (such as radio, television, newspapers, etc.), and information can also be displayed through Internet and related technologies of the Internet of Things. Normally, face-to-face training of service providers often enables farming operators to grasp the relevant breeding skills more quickly. Jiangsu Agriculture Information Network has set up special columns for industries and services to provide such information as grain and oil industry, aquaculture, special livestock and poultry, forestry processing and other production information and provide long-distance video and online consultation services. It not only provides agricultural production and operators rich Information resources, and through the analysis of agricultural forecasting early warning report, provide a reference for agricultural production decision-making. The application of emerging technologies is the focus of modern agricultural information service, and it is also an important means to increase agricultural production efficiency and increase production and income. Agricultural production solutions (such as smart greenhouses, smart irrigation and fertilization, etc.) are important services for the application of IOT technology in agriculture. They facilitate the transformation of agricultural production service modes. At present, all kinds of agriculture-related Internet of Things and IT enterprises provide rich solutions for agricultural production and strive to meet the diversified information needs of service objects. Jiangsu middle peasants Network Technology Co., Ltd., Su Mei-lun Intelligent Technology Co., Ltd. and a number of the province's Internet of Things enterprises, with its own technological advantages, to provide a wealth of agricultural intelligence solutions.

\section{Agricultural Information Service System Optimization Countermeasures}

First, the government should change its service role. Jiangsu agricultural information service is mainly organized by Jiangsu Provincial Committee of Agriculture and relevant agricultural departments. The government plays a crucial role in the integration and utilization of agricultural information resources. However, excessive government intervention will hinder the innovation and development of related industries. Therefore, the dominant position of the government in agricultural information service should be changed and decentralized. For example, the establishment of Jiangsu Provincial Agricultural Information Service Management Committee, the introduction of agricultural management households, agricultural-related enterprises, university research institutions should be fully involved in the discussion and formulation of related decisions;

Second, the government should fully mobilize the enthusiasm of other service providers. We can use such means as financial subsidies, policy support, credit, interest rates and taxation to encourage all investors and service providers to intervene and enrich the main body of the system so as to diversify the main body of agricultural information services and the investment structure. For example, a special agricultural information service fund is set up in Jiangsu Province to support the investment and construction of agricultural informatization construction projects in all the cities in the province. The management and operation of the fund can be actively introduced into private capital while giving certain policies to the special fund to tilt and ensure reasonable ROI.

Finally, the government should step up the promotion of information technology in agricultural information services, support related industries through multiple means, and create a good 
agricultural information service environment. Currently, the government of Jiangsu Province only subsidizes some agricultural IOT demonstration parks. The government freely purchases IoT devices for agricultural operators and provides funding for maintenance. However, as a whole, the population has a relatively narrow benefit. Therefore, the provincial government departments in charge of agriculture may, through bidding, collectively purchase smart agricultural related equipment at reasonable prices for agricultural operators in need and come up with a certain budget to encourage the promotion of advanced technologies. Advanced information technology is an important tool to improve the quality of agricultural information service. Changes in production and lifestyles brought about by technological innovations are obvious to all. At present, the application of Jiangsu Internet of Things is in the initial stage of research and development and application and promotion, and its application prospect is very broad. Therefore, we must step up R \& D to encourage related information technologies such as the Internet of Things and promote its transition to a mature stage of technology and the transformation of production results.

\section{Conclusion}

The agricultural information service based on Internet of Things is a long-term and complex systematic project. It is an important part of the transformation and upgrading of China's modern agriculture and requires all parties involved in the service industry to participate in and cooperate with each other in order to achieve the corresponding service effect. To promote the integration of Internet of Things technology with the construction of agricultural information service system is also a need to enhance the level of agricultural science and technology and promote the sustainable development of agricultural economy.

\section{Acknowledgement}

Project: Science and Technology Development Project of Jilin Province Natural Science Foundation of China: Application of Wireless Sensor Network to the Monitoring Technology of Ginseng Growth Environment Parameter.

Project No.: 20150101099JC

Jilin Province Science and Technology Agency Development Plan Science and Technology Innovation Center base and technology service platform construction project: Internet + ginseng ecological factor analysis and prediction information service platform.

Key disciplines of Jilin Agricultural Science and Technology Training Program: Research on Ginseng Growth Environment Parameter Monitoring System Based on Internet of Things.

Project No.: Jilin Agricultural Academy of Sciences [2015] No. X097

\section{References}

[1] Koshizuka N, Sakamura K. Ubiquitous ID: Stardards for ubiquitous computing and the Internet of Things[J]. IEEE Pervasive Computing,2010,9(4):98-101.

[2] Presser M, Barnaghi P M, Eurich M, Villalonga C. The SENSEI project: Integrating the physical world with the digital world of the network of the future[J]. Global Communications Newsletter, 2009, 47(4):1-4.

[3] Atzori L, Iera A. The Internet of Things: A survey[J]. Computer Networks, 2010, 54 (15): 2787-2805.

[4] Kortuem G, Kawsar F, Fitton D, Sundramoorthy V. Smart objects as building blocks for the Internet of Things[J]. IEEE Internet Computing,2010,14(1):44-51.

[5] Shim Y, Kwon T, Choi Y. SARIF: A novel framework for integrating wireless sensors and RFID networks[J]. IEEE Wireless Communications,2007,14(6):50-56. 